\title{
Da crítica de Nietzsche ao sujeito ao sujeito de sua crítica
}

\author{
Antonio Edmilson Paschoal ${ }^{*}$
}

\begin{abstract}
Resumo: A ambiguidade do título deste artigo reflete o caráter multifacetado de um problema que tem no seu horizonte, por um lado, a dura crítica de Nietzsche ao sujeito e, por outro, as possibilidades abertas por essa crítica, seja na direção de um sujeito plural, tese claramente delineada nos escritos de Nietzsche, seja no sentido de um sujeito ficcional, que aparece em seus textos contrariando a ideia de sujeito criticada por ele. Tendo em vista, portanto, o caráter controverso da questão, o propósito deste estudo é apontar alguns traços centrais da crítica de Nietzsche ao sujeito no intuito de mostrar que é justamente a partir dessa crítica que são delineadas novas possibilidades para pensar e utilizar a ideia de sujeito em seus escritos.
\end{abstract}

Palavras-chave: Nietzsche, sujeito, subjetividade, crítica, autogenealogia.

* Professor do Departamento de Filosofia da Universidade Federal do Paraná, Curitiba, PR, Brasil. Pesquisador do CNPq.

Correio eletrônico: antonio.paschoal@yahoo.com.br 
Paschoal, A. E.

\section{Apresentação da questão}

Por um longo tempo, ao voltar-se sobre o tema do sujeito, a recepção do pensamento de Nietzsche concentrou-se quase exclusivamente na crítica radical do filósofo à ideia de sujeito que se tem na cultura ocidental e que aparece com designações como "eu", "alma", "substância" etc. ${ }^{1}$ No âmbito dessa recepção, ganhou forma clara uma oposição que considera, por um lado, um conceito de sujeito entendido como um pressuposto para o pensamento e para a ação, uma individualidade capaz de conhecer o mundo e a si mesmo e deliberar livremente por seus atos e, por outro, a crítica radical de Nietzsche a essa ideia, desenvolvida como parte de sua ofensiva contra a metafísica. ${ }^{2}$ No domínio dessa oposição, o filósofo terminaria por postular que o conceito de sujeito não passaria de uma falsificação, um equívoco, visto ser parte de uma forma simplificada de ver o mundo e as coisas. Algo a ser descartado juntamente com outras ideias associadas a ele, como a de substância, causa e efeito etc. Haveria, portanto, uma incompatibilidade entre a ideia de sujeito e a filosofia de Nietzsche, que terminaria por negar a possibilidade de se conceber tal ideia ou de trabalhar com semelhante conceito.

Tal abordagem crítica, contudo, não parece encerrar toda a complexidade da questão do sujeito na filosofia de Nietzsche, antes, permite vislumbrar apenas um primeiro horizonte muito vago e difuso do tema. Mais ainda, se for considerado apenas aquele patamar crítico-corrosivo, um leitor supostamente atento se depararia com algumas incongruências na filosofia de Nietzsche. Por exemplo, esse leitor terminaria por afirmar que aquela crítica mesma é conduzida

1 François Kammerer apresenta um arrazoado da recepção francesa no qual se tem alguns exemplos do modo como a filosofia de Nietzsche culminaria na negação do sujeito. Segundo ele, isso ocorre mesmo com filósofos franceses contemporâneos, como é o caso, por exemplo, de Judith Butler (Kammerer, 2008, pp. 13-14).

20 principal exemplo nesse sentido é Heidegger. Para ele, a crítica de Nietzsche ao sujeito é parte da crítica do filósofo à metafísica (Heidegger, 2007, pp. 94-151).

94 | Cad. Nietzsche, Guarulhos/Porto Seguro, v.39, n.1, p. 93-119, janeiro/abril, 2018. 
por um sujeito que se manifesta no texto: o "senhor Nietzsche" (FW/GC Prólogo 2, KSA 3.347). Ou seja, na própria construção argumentativa do filósofo se evidenciaria o fato mais elementar de que um discurso é sempre produzido por um sujeito interessado em produzir efeitos, por exemplo, no caso, sobre seus leitores. Um sujeito que, de resto, responde por esses efeitos, além de se comprometer pelas posições tomadas em seus escritos. ${ }^{3}$ A Nietzsche, portanto, não restaria alternativa a não ser admitir o fato de que é como um sujeito que conduz a sua crítica à ideia de sujeito e, por conseguinte, reconhecer que ele mesmo ficaria preso nas malhas da gramática que critica, permanecendo enleado em idiossincrasias como as de causa e efeito, das quais não conseguiria se livrar ao falar e atuar (FW/GC 347, KSA 3.581-583).

Conforme veremos, porém, o surgimento dessas incongruências ocorre apenas quando a filosofia de Nietzsche é lida como se fosse parte da metafísica criticada por ele, como se ela operasse a partir do "hábito das oposições" (WS/AS 67, KSA 2.582), vendo nas coisas elementos contrários que se excluem ao modo do certo ou errado, verdadeiro ou falso, sim ou não. Como se também Nietzsche atuasse nos limites estreitos da "crença fundamental dos metafísicos" (JGB/BM 2, KSA 5.16), segundo a qual não existe, por exemplo, a possibilidade de um enunciado ser verdadeiro e falso ao mesmo tempo, assim como a possibilidade de uma terceira alternativa para o antagonismo entre verdadeiro ou falso. De fato, caso se mantivesse em tais limites, Nietzsche se tornaria estranho à ideia de um espírito livre, este último disposto a pensar para além desses antagonismos e a buscar um "estado intermediário", no qual as oposições dariam lugar, por exemplo, a um "terceiro termo" (MA I/HH I, Prefácio 4, KSA 2.18).

Deslocando-se, contudo, para longe daquelas incongruências demasiadamente triviais e gestadas no interior de uma leitura que

3 Conferir a ideia de "compromisso" em EH/EH Por que sou tão sábio 7, KSA 6.274. 
pouco acrescentaria ao debate sobre a questão do sujeito, a recepção do pensamento de Nietzsche tem se mostrado bem mais fecunda no tratamento do tema nos últimos anos. ${ }^{4}$ Especialmente quando deixou de considerar como única alternativa para a filosofia de Nietzsche a exclusão do sujeito, passando a colocar em relevo a possiblidade de um sujeito plural e a ressignificação operada por Nietzsche daquela concepção tradicional de sujeito.

Acompanhando essas pesquisas e buscando marcar uma posição no atual debate acerca do sujeito na filosofia de Nietzsche, este artigo apresenta como hipótese central que, para além daquela oposição que terminaria por excluir a possibilidade do sujeito, é possível divisar na argumentação do filósofo um conjunto de estratégias filosóficas e recursos de linguagem que permitem vislumbrar novas possibilidades para o velho tema do sujeito. ${ }^{5}$ Possibilidades que não ocorrem a despeito da crítica de Nietzsche ao sujeito, numa direção contrária a ela, ${ }^{6}$ mas, antes, surgem como um desdobramento, um resultado obtido por ele justamente dessa crítica. ${ }^{7}$

4. E não apenas nos últimos anos, pois vários estudos atuais sobre o tema do sujeito e da subjetividade em Nietzsche retomam, por exemplo, a conceitos abertos por Foucault, que sinaliza para a possibilidade de se pensar sujeitos na filosofia de Nietzsche, em contraposição à ideia moderna da unidade do sujeito (Foucault, 2002, p. 20). É interessante observar ainda, em relação a Foucault, que a noção de subjetividade que se tem em sua filosofia permite a alguns intérpretes retomarem o tema do sujeito nos escritos de Nietzsche. Algo observado nos trabalhos de Martin Saar (2007) e explicitado por François Kammerer (2008, p. 17).

5 Como já foi mencionado pela referência aos trabalhos de Saar e Kammerer, e indiretamente a Foucault, essa tese não é nova. Mais recentemente, ela é retomada por João Constâncio, que igualmente parte do princípio de que Nietzsche não realizaria uma negação do sujeito em geral, mas da ideia de sujeito como unidade, o que daria lugar à hipótese de um sujeito entendido como uma multiplicidade (Constâncio, 2015, p. 290). Ainda, segundo Constâncio, o que permite a Nietzsche superar o debate sobre o sujeito que se tem na modernidade é a introdução da noção de "subjetividade" (Constâncio, 2015, p. 314).

6 Vale ressaltar que a crítica de Nietzsche a algo não implica na afirmação do oposto do que é criticado, como seria o caso, por exemplo, de optar pelo "cativo arbítrio" ao criticar o "livre arbítrio" (JGB/ BM 21, KSA 5.35).

70 que se pretende aqui é dar alguns passos na senda aberta por outros estudos que, no Brasil, ganharam forma, por exemplo, dos trabalhos de Alberto Onate (2000) e Luiz da Mota Itaparica (2011). $\mathrm{O}$ primeiro que acompanha a tese da associação entre a crítica ao sujeito e a crítica à metafísica na filosofia de Nietzsche e o segundo que defende o princípio de que a crítica do filósofo não exclui a

$96 \mid$ Cad. Nietzsche, Guarulhos/Porto Seguro, v.39, n.1, p. 93-119, janeiro/abril, 2018. 
Para sopesar esta hipótese, de que novas possibilidades de se pensar o tema do sujeito são delineadas a partir da crítica de Nietzsche ao sujeito, serão apresentados a seguir algumas breves notas sobre essa crítica e, a partir delas, avaliadas algumas passagens dos escritos do filósofo nas quais é possível falar em sujeito(s), primeiro, como uma pluralidade de forças e impulsos vinculados ao corpo e explicitados de forma precária pela linguagem e, segundo, como uma ficção, quando o sujeito não corresponde a uma unidade e nem a uma pluralidade, mas a uma máscara. Duas possibilidades que, conforme veremos, se intercruzam ao mesmo tempo em que deslocam o sujeito da ideia de substância até a de personagem e recurso filosófico.

\section{Breves notas sobre a crítica de Nietzsche ao sujeito}

Em linhas gerais, a crítica de Nietzsche se dirige àquela concepção que compreende o sujeito como uma unidade autônoma, capaz de conhecer a si mesmo e o mundo ao seu redor e de tomar decisões e agir livremente nesse mundo. No seu extremo, um "puro sujeito do conhecimento, isento de vontade, alheio à dor e ao tempo", capaz de uma "observação desinteressada" (GM/GM, III 12, KSA 5.364) e de uma ação livre de qualquer forma de condicionamento. Uma concepção que teria por pressuposto um "homem objetivo" (JGB/ BM 207, KSA 5.135), ao qual se associaria ainda a superstição de uma "liberdade da vontade" e (JGB/BM 19, KSA 5.32) diante do qual se colocaria um "objeto puro", a ser apreendido independentemente de qualquer amor, ódio ou falsificação.

\footnotetext{
ideia de subjetividade, mas a depura dos pressupostos metafísicos nos quais ela estaria arraigada. Merece relevo o fato de Itaparica partilhar da ideia de que a crítica de Nietzsche ao sujeito não impede uma retomada do tema nos seus escritos, o que ocorre tendo em vista a hipótese do corpo entendido como uma "estrutura social de impulsos e afetos" (Itaparica, 2011, p. 74).
} 
Para Nietzsche, ainda em linhas gerais, tal concepção estaria vinculada a crenças primitivas, como a crença no "eu" e na "alma". Crenças que não passariam de "preconceitos populares" (JGB/BM 19, KSA 5.32) sedimentados pela religião e sistematicamente reafirmados pelos filósofos, que acreditavam criticar a religião sem, no entanto, se desvencilharem de seus pressupostos básicos, justamente as ideias de alma e de imputabilidade, traduzidas por aqueles filósofos por meio de conceitos como de "sujeito e predicado" (JGB/BM 54, KSA 5.73).

Esse contrassenso dos filósofos ocorreria, segundo Nietzsche, porque eles não teriam conseguido se desvencilhar da "sedução da linguagem" (GM/GM I, 13, KSA 5. 280) e, por decorrência, teriam conferido um estatuto de realidade a certos "hábitos gramaticais" (JGB/ BM 17, KSA 5.31). O que se verificaria no fato de eles conceberem o "eu" como sujeito do pensamento e vincularem esse sujeito que pensa e age a uma "substância "verdadeira a priori" (Nachlass/FP, 1887 10[158], KSA 12.549), uma "causa sui" (JGB/BM 21, KSA 5.35), sancionando, assim, a expectativa pela causalidade e a necessidade de um agente como condição para se compreender uma ação. ${ }^{8} \mathrm{O}$ sujeito corresponderia, porquanto, a uma terminologia para a "nossa crença em uma unidade subjacente em todos os diferentes momentos do mais elevado sentimento de realidade", ao fato de "entendermos essa crença como efeito de uma causa, ${ }^{9}-[\mathrm{e}]$ acreditamos em nossa crença de tal maneira que, em função dela, imaginamos em geral a

8 Sob esse aspecto, a crítica de Nietzsche à noção de sujeito é também uma crítica à noção de causalidade, ao estabelecimento de uma relação obrigatória entre causa e efeito. Sob esse aspecto também, a crítica de Nietzsche ao sujeito associa-se a uma crítica a uma concepção de mundo regido por leis mecânicas invariáveis. O desafio que se apresenta para Nietzsche, nesse sentido, é de lançar mão das possibilidades apresentadas a ele pela linguagem para expressar, ao menos em parte, a complexidade de uma concepção de mundo regido por forças que se relacionam num vir a ser em que "a ação é tudo" (GM/GM I 13, KSA 5.279).

9 Na seção 6, intitulada "Das causas imaginárias", do capítulo "Os quatro grandes erros", do Crepúsculo dos Ídolos (KSA 6.94-95) Nietzsche apresenta uma das formulações mais claras sobre o modo como o estabelecimento de causas a todo acontecer é uma decorrência do modo como a nossa razão apreende as coisas, como parte de nossa própria exigência de nos tornarmos "conscientes" daquilo que se passa ao nosso redor.

98 | Cad. Nietzsche, Guarulhos/Porto Seguro, v.39, n.1, p. 93-119, janeiro/abril, 2018. 
'verdade', a 'efetividade', a 'substancialidade"'. (Nachlass/FP, 1887 10 [19]; KSA 12.465)

Um papel chave nessa crítica é desempenhado pela ideia de ficção, entendida como um equívoco da razão que "introduz uma falsa realidade" (Nachlass/FP, 1887 9[144], KSA 12.417) e passa a acreditar nela como sendo, de fato, real. No caso, o equívoco consiste em acreditar que "muitos estados iguais em nós seriam o efeito de um único substrato". Em oposição a esse equívoco da razão, Nietzsche afirma que fomos nós mesmos os criadores dessa ficção, pois "fomos nós mesmos que criamos a 'igualdade' desses estados; o igualar e o arranjar deles é a sua realidade e não a igualdade". (Nachlass/FP, 188710 [19], KSA 12.465)

Na história da filosofia, essa concepção de um sujeito separado da ação teria uma primeira formulação entre os antigos, em especial com a ideia de um sujeito puro do conhecimento que Nietzsche associa quase sempre a Platão (por exemplo, em JGB/BM Prólogo, KSA 5.12) e eventualmente a Aristóteles (Nachlass/FP, 1884 25[17], KSA 11.16). ${ }^{10}$ Ela ganharia relevo, contudo, entre os modernos, principalmente com Descartes ${ }^{11}$ e Kant ${ }^{12}$, sendo as referências de Nietzsche ao primeiro mais constantes (mas não exclusivamente) quando se trata da crítica ao sujeito do conhecimento, e ao segundo quando se trata do sujeito livre tomado como pressuposto para a ação moral.

Considerando o primeiro caso - a crítica ao sujeito do conhecimento - o que se observa é o destaque conferido por Nietzsche

10 Embora Nietzsche faça menção à ideia de sujeito entendida como substância, são raríssimas as referências que permitiriam associar a ideia de substância criticada por ele à ideia de sujeito como substância (hypokeimenon) que se encontra na filosofia de Aristóteles, por exemplo, no livro VII da Metafísica.

11 Conforme veremos, Nietzsche tem no horizonte em especial as Meditações de Descartes e seu Discurso do método.

12 No caso de Kant, a principal referência será a ideia de um sujeito livre, entendida como um pressuposto do agir moral, que se encontra diluída na Crítica da razão prática e na Fundamentação da filosofia dos costumes. 
Paschoal, A. E.

à associação desse sujeito, designado pelo termo "eu", ao predicado "penso". Uma associação que ele identifica de forma privilegiada em Descartes, em cujo pensamento encontra "uma série de afirmações temerárias" tais como: "que sou eu quem pensa, que deve haver necessariamente um algo que pensa, que pensar é atividade e efeito de um ser que é pensado como causa, que existe um 'eu' e, por fim, que já está firmemente estabelecido o que deve ser designado como pensar, que eu sei, o que é pensar" (JGB/BM 16, KSA 5.30). Afirmações que corroboram a existência de um eu como um sujeito cujo efeito, sua ação, seria o pensamento. Um modo de fazer filosofia que não abandona a ideia de um "eu" mesmo quando no seu limite esse eu é traduzido como um "isso" (es) que pensa, expressando, assim, a dificuldade básica presente em nossa cultura de se pensar sem ao menos o "isso". ${ }^{13}$ Para Nietzsche Descartes seria, portanto, um exemplo privilegiado tanto daquele vínculo da filosofia com a linguagem quanto daquele contrassenso dos filósofos, pois ele teria tomado um eu pensante, o cogito, como uma "certeza imediata" (JGB/BM 16, KSA 5.30) e o teria estabelecido como o pressuposto sobre o qual assentaria a sua filosofia.

Contudo, apesar da constatação de que Nietzsche empreende uma dura crítica aos filósofos modernos em geral e a Descartes em particular, quando se trata do sujeito do conhecimento, e a despeito da "enorme distância que se põe entre eles [Nietzsche e Descartes]", como lembra Scarlett Marton, ${ }^{14}$ não se poderia deixar de observar que a crítica de Nietzsche a Descartes não constitui um não absoluto ao modo como Descartes procede para a construção e exposição de sua filosofia, mas uma exigência de um rigor maior na aplicação

13 Na língua alemã é ainda mais difícil falar sem o "isso" (es) do que no português. Por exemplo, a nossa expresão "chove" ou "está chovendo" não pode ser dita em alemão sem a adição do pronome pessoal neutro "es" (isso), no caso, "es regnet".

14 Marton, 2009, p. 151. Conforme lembra Marton, a Nietzsche não interessa construir um sistema de pensamento. Seu propósito não é de encerrar o pensamento "nos limites estreitos de uma dogmática", (Marton, 2009, p. 155), como faz Descartes.

$100 \mid$ Cad. Nietzsche, Guarulhos/Porto Seguro, v.39, n.1, p. 93-119, janeiro/abril, 2018. 
por Descartes do seu método da dúvida. De fato, para Nietzsche, Descartes teria abandonado demasiadamente cedo seu propósito "omnibus dubitandum [de duvidar de tudo]" (JGB/BM 2, KSA 5.16) e aceitado rápido demais o eu como uma certeza imediata. ${ }^{15}$

Mais ainda, é possível afirmar que Nietzsche apresenta um grande respeito e um claro reconhecimento para com Descartes. $\mathrm{O}$ que fica evidenciado, por exemplo, quando ele utiliza uma passagem do Discurso do Método "em lugar de prefácio" na primeira edição de Humano, demasiado humano. ${ }^{16}$ Esse reconhecimento, contudo, ganha contornos ainda mais contundentes quando ele lança mão de um tipo de escrita na forma de uma narrativa de sua própria trajetória, em primeira pessoa do singular, semelhante ao que faz Descartes em O Discurso do Método e nas Meditações, por exemplo, ao escrever Ecce Homo e também, de forma menos acentuada, no prefácio da Genealogia da moral e nos conhecidos prefácios de 1886. Uma semelhança já apontada por Scarlett Marton ${ }^{17}$ e ressaltada por Isabelle

15 A argumentação de Nietzsche pode ser acompanhada passo a passo na conhecida seção 16 de Além de bem e mal, dirigida a Descartes.

160 texto, traduzido do latim por Nietzsche da terceira parte das Meditações de Descartes, é o seguinte: " - Durante certo tempo, examinei as diferentes ocupações às quais os homens se entregam nesta vida, e fiz a tentativa de escolher a melhor entre elas. Porém, não é necessário relatar aqui os pensamentos que então me vieram a respeito: é suficiente dizer que, de minha parte, nada parecia melhor do que me ater firmemente ao meu propósito, ou seja, empregar todo o tempo da vida em cultivar minha razão e perseguir a trilha da verdade no estilo de vida que eu havia proposto para mim. Isto ocorreu porque os frutos que eu já havia provado neste caminho eram tais que, segundo meu julgamento, nada poderia ser encontrado nesta vida que fosse mais agradável e inocente; então, depois de me socorrer daquela forma de reflexão, cada dia me fez descobrir algo novo, que tinha alguma importância e não era em absoluto de conhecimento geral. Então, finalmente minha alma se encheu de tamanha alegria que nada mais poderia incomoda-la". (MM/HH Em lugar de um prefácio, KSA 2.11) O texto, vertido diretamente do latim por Nietzsche, com algumas variações devido a opções de tradução, encontra-se em: DESCARTES, René. Discurso do Método. As paixões da alma. Meditações. Objeções e respostas. Trad. de J. Guinsburg e Bento Prado Junior. $5^{\text {a }}$ ed. São Paulo: Nova cultural, 1991, (Os Pensadores), p. 43 ("Enfim, para a conclusão dessa moral, deliberei passar em revista as diversas ocupações..."). Nesse texto, e em outros, evidencia-se que as conclusões de Descartes não são produtos de um empreendimento lógico apenas.

17 Marton, 2009, p. 154. Scarlett Marton enfatiza que ambos, Nietzsche e Descartes, "deixaram entrever, em suas obras, a íntima relação entre filosofia e vida”, sem deixar de notar também que "seria ingênuo supor que o Discurso se confunde com uma autobiografia ou um livro de memórias" 
Wienand, que vê na concepção de sujeito veiculada por Nietzsche um conceito construído a partir da noção cartesiana de "eu", que é tomada como um contraponto de primeira ordem para formular sua crítica ao sujeito. ${ }^{18}$ Conforme veremos adiante, no item 4, o uso do pronome pessoal "eu" por Nietzsche, semelhante a Descartes, se configura como uma das possibilidades mais interessantes de se pensar o sujeito em seus escritos.

Considerando o segundo caso - a crítica ao sujeito entendido como pressuposto da ação - ganha destaque a liberdade do sujeito para decidir acerca do seu agir. Nesse sentido, um dos textos mais conhecidos para a abordagem do tema é a seção 13 da primeira dissertação da Genealogia da moral, onde o filósofo escreve:

Um quantum de força equivale a um mesmo quantum de impulso, vontade, atividade - ou melhor, não é nada mais que esse mesmo impulso, vontade e atividade mesmo, e apenas sob a sedução da linguagem (e dos erros fundamentais da razão que nela se petrificam), a qual entende e mal-entende todo atuar como sendo determinado por um atuante, por um "sujeito", e só por isso pode parecer diferente. Pois assim como o povo separa o raio do clarão, e toma o segundo como ação, como efeito de um sujeito de nome raio, do mesmo modo a moral do povo separa também a força das exteriorizações da força, como se por trás do forte houvesse um substrato indiferente que seria livre para exteriorizar ou não a força. Porém, não existe um tal substrato; não existe qualquer "ser" por trás da ação, da atividade, do devir; "o agente" é uma fantasia acrescentada à ação - a ação é tudo. (GM/GM I, 13, KSA 5.279)

(p. 151). Nesse ponto, ela afirma que a "biografia intelectual do autor", no caso de Descartes, conduz a "verdades universais, que constituem o sistema do filósofo" (Marton, 2009, pp. 152153). O que faria "ruir por terra a tentativa de aproximar Descartes e Nietzsche" (p. 157). Ao lado dessa irrefutável conclusão, contudo, ressaltamos a semelhança entre ambos do ponto de vista de um modo de escrita em primeira pessoa que de fato não se confunde com uma autobiografia, mas corresponde a uma estratégia de artista, utilizada por Descartes e que Nietzsche lança mão, ao certo para chegar a resultados diferentes daqueles obtidos por Descartes. Nesse sentido, mais do que enfatizar as diferenças nas conclusões de ambos, interessa neste artigo observar a maneira como Nietzsche confere, também nesse caso, "a um olhar tão agudo e imparcial uma direção melhor" (GM/GM, Prefácio 7, KSA 5.254).

18 Wienand, 2015, p. 49.

102 | Cad. Nietzsche, Guarulhos/Porto Seguro, v.39, n.1, p. 93-119, janeiro/abril, 2018. 
Focada na hipótese de uma liberdade para decidir entre atuar ou não, a crítica de Nietzsche ao sujeito remonta ao início de sua crítica à moral e é observada, por exemplo, no aforismo 116 de Aurora, intitulado "O mundo desconhecido do "sujeito", onde faz menção à ignorância que recobre o modo "como se produz a ação humana", quando ela é considerada como o produto deliberado de um sujeito unitário possuidor de uma vontade livre. Nessa passagem, dando voz a um suposto interlocutor, Nietzsche afirma ironicamente: "eu sei o que quero, o que fiz, eu sou livre e responsável por isso, eu torno o outro responsável, eu posso nomear todas as possibilidades morais e todos os movimentos interiores que antecedem uma ação; vocês podem agir como preferirem, - nisso eu conheço a mim e a todos vocês". (M/A 116, KSA 3.108). Também em outros textos posteriores o núcleo da crítica ao sujeito, tomado do ponto e vista da ação, será a noção de "livre arbítrio" ou de "vontade livre" (GD/ CI, Os quatro grandes erros 7, KSA.95), que na interpretação de Nietzsche está intimamente ligada às ideias de responsabilidade e de imputabilidade, cuja plausibilidade só pode ser conferida a partir daquela hipótese de um sujeito livre.

Em termos filosóficos, essa noção de um sujeito estaria associada a dois postulados básicos. $\mathrm{O}$ primeiro seria a crença na ideia de "causa sui", que toma o homem como causa de si mesmo e, assim, responsável por suas ações, desobrigando delas "Deus, mundo, ancestrais, acaso, sociedade", etc... (JGB/BM 21, KSA 5.35). Algo que só poderia ser verificado, segundo Nietzsche, ironicamente, na fantasia do Barão de Münchhausen de arrancar "a si mesmo pelos cabelos do pântano do nada em direção à existência" (JGB/BM 21, KSA5.35). O segundo diz respeito à ideia atribuída a Sócrates e Platão, de que "a ação correta deveria derivar necessariamente do correto conhecimento" (M/A 116, KSA 3.108), ao postulado de que o conhecimento de uma ação, o fato de alguém ter ciência das 
suas consequências seria causa suficiente para deliberar por sua realização ou não. Como se pode observar, nesse e em outros casos, a crítica de Nietzsche não se dirige a uma ideia geral de liberdade, mas a uma acepção específica de livre arbítrio que ele denomina como uma "superlativa acepção metafísica" (JGB/BM 21, KSA 5.35) de vontade livre. Um acepção especialmente cara ao cristianismo que toma esse livre arbítrio ${ }^{19}$ como um pressuposto inseparável da promessa futura de salvação ou perdição da alma, (GD/CI, Os quatro grandes erros 8, KSA 6.96-97) e que ganha contornos peculiares na modernidade com Kant, o filósofo que teria conferido um caráter laico e científico aos velhos e desacreditados pressupostos religiosos. Kant, um caso exemplar de sedução moral (M/A Prefácio 3, KSA.1314) e que ganha importância para Nietzsche ao postular a ideia de liberdade associada a uma causalidade da vontade ${ }^{20}$ como condição elementar para o agir moral. Para o filósofo de Königsberg, a vontade livre seria um pressuposto indispensável para a obrigação e para a subsequente imputação moral.

Contudo, do mesmo modo como se verificou na correlação entre Nietzsche e Descartes, também a crítica à ideia de sujeito livre de Kant, não equivale simplesmente a assumir uma posição contrária à de Kant, ou negar os benefícios introduzidos por ele no debate sobre o sujeito. Nesse sentido, vale observar que é plausível a aproximação da ideia de "ficção reguladora" (FW/GC 344, KSA 3.574), postulada por Nietzsche, com a ideia de sujeito como um

19 Duas formulações clássicas da ideia de livre arbítrio na tradição cristã são as de Agostinho, em especial no Livro VIII das Confissões (1973, p. 151-167) e de Tomás de Aquino, na 24a de suas "questões disputadas" cujo título é justamente O livre arbítrio (2015, p. 45-74).

200 tema é central na filosofia prática kantiana. A título de exemplo, mencionamos a terceira seção da Fundamentação da metafísica dos costumes, intitulada " $\mathrm{O}$ conceito de liberdade é a chave para a explicação da autonomia da vontade", em especial onde se lê: "A vontade é uma espécie de causalidade dos seres vivos, na medida em que são racionais, e a liberdade seria a propriedade dessa causalidade que permite a ela atuar independentemente de causas determinantes que seriam estranhas a ela" (KANT, 1996, p. 81).

104 | Cad. Nietzsche, Guarulhos/Porto Seguro, v.39, n.1, p. 93-119, janeiro/abril, 2018. 
"operador lógico" que se tem na Crítica da razão pura, ${ }^{21}$ lembrando que Nietzsche reconhece em Kant o estabelecimento do "penso" como condição e do "eu" como condicionado, isto é, do "eu" como "uma síntese realizada pelo próprio pensamento", permitindo postular que "a possibilidade de uma existência aparente do sujeito" não seria estranha a Kant (JGB/BM 54, KSA 5.73). Do mesmo modo como é plausível a hipótese de uma aproximação entre a ideia de liberdade que se tem na segunda dissertação da Genealogia da moral, associada à figura do "Indivíduo Soberano" (GM/GM, II 2, KSA 5.293), e a ideia de uma liberdade, não como pressuposto, mas como resultado do agir moral, no sentido kantiano. ${ }^{22}$

Portanto, o que é central, tanto no caso de Descartes, quanto no de Kant, é que a crítica não implica simplesmente na tentativa de refutar uma teoria ou, no seu extremo, de eliminar um oponente. Como se as únicas opções fossem ou aceitar a ideia de um sujeito livre, ou a excluir qualquer possibilidade de um sujeito. Isso não apenas porque Nietzsche se dirige especificamente àquela "superlativa acepção metafísica de livre arbítrio" (JGB/BM 21, KSA 5.35), mas também porque seu objetivo não é extinguir toda e qualquer hipótese do sujeito ou possibilidade de uso do conceito, e sim sair daquela "rede" que corresponde ao modo como a metafísica procede ao tratar o tema (JGB/BM 2, KSA 5.16-17). Um modo de pensar por oposições que, por fim, "nos induziu a querer entender e decompor segundo essas oposições também a natureza interior, o mundo éticoespiritual". Algo que Nietzsche não assume em sua crítica, pois, conforme vimos, para ele não existem oposições nas coisas, "mas apenas diferenças de grau" entre elas e, em se tratando daquele mundo interior, o que se tem são, antes, "transições" (WS/AS 67, KSA 2.582) entre diferentes graus.

21 Kant, 1995, p. 273 . O sujeito, no caso, funciona como um operador lógico, deixando de pressupor uma existência real ou a condição de substância.

22 Em função das suas implicações e desdobramentos, essas hipóteses sobre a correlação possível entre as filosofias de Nietzsche e Kant serão retomadas em outro momento. 
Do mesmo modo, a compreensão da crítica de Nietzsche ao sujeito torna-se bem mais interessante quando se deixa de lado aquela dualidade excludente que só ofereceria como opções ou um livre arbítrio e uma moralidade, ou um "cativo arbítrio" (JGB/ BM 21. KSA 5.35) e a ausência de qualquer possibilidade de ação moral ou de responsabilidade. Caso contrário, seria difícil até mesmo confrontar a sua crítica ao sujeito com as passagens em que ele fala de um comprometimento (EH/EH, Por que sou tão sábio 7.274) ou de responsabilidade (GM II 2) ou, ainda, em um engajamento por formas mais elevadas de vida. ${ }^{23}$ De fato, compreender Nietzsche e as concepções de sujeito possíveis em sua filosofia implica em abandonar aquele dualismo que reduz o todas as coisas a negativo e positivo, verdadeiro e falso, "sim e não" (MA I /HH I, Prólogo 4, KSA 2.18), e se colocar num horizonte em que o mundo é visto como uma pluralidade de forças em conflito e o corpo como uma "estrutura social de muitas almas" (JGB/BM 19. KSA 5.33), uma complexa configuração de vontades, forças e instintos, numa permanente tensão.

\section{Do sujeito como unidade ao sujeito como uma pluralidade em conflito}

A primeira possibilidade a ser considerada quando se trata de uma concepção de sujeito na filosofia de Nietzsche ao sujeito diz respeito àquela configuração complexa, permeada pelas mais diversas circunstâncias e que só é reconhecida quando se toma o

23 Refiro-me, por exemplo, à proposição do filósofo que se encontra em $O$ Anticristo: "não é o que se sucederá à humanidade na sequência dos seres (- o homem é um final -), o problema que coloco aqui; mas sim que tipo de homem deve-se cultivar, deve-se querer, como o de mais alto valor, mais digno de vida, o mais certo de futuro" (AC/AC 3, KSA 6.170). O que não se confunde com um "espírito cultivado" no sentido de um homem instruído academicamente, por exemplo, mas corresponde à ideia de um "espírito vigoroso e independente" (JGB/BM 39. KSA 5.57), ou simplesmente, de "homens de exceção, da mais perigosa e atraente qualidade", (JGB/BM 242; KSA 5, p. 183), cuja preparação seria feita por meio de "grandes empresas e tentativas amplas de disciplina $[Z u c h t]$ e cultivo [Züchtung]" (JGB/BM 203, KSA 5.126) ou, em termos pessoais, por uma dura "disciplina [Zucht] e cultivo [Züchtung] espiritual" (JGB/BM 188, KSA 5.109).

106 | Cad. Nietzsche, Guarulhos/Porto Seguro, v.39, n.1, p. 93-119, janeiro/abril, 2018. 
homem "a partir do fio condutor do corpo" (Nachlass/FP, 1884, 27 [27], KSA 9.262). ${ }^{24}$ Em contraposição à ideia de sujeito entendido como uma substância inalterável, uma unidade que pensa e decide livremente por suas ações, deriva da crítica de Nietzsche à ideia de um sujeito entendido como uma pluralidade fluida.

Tal derivação ganha forma, por exemplo, numa anotação pessoal de Nietzsche (Nachlass/FP, 1887, 9 [98], KSA 12.391), onde ele retoma a crítica à associação entre o "sujeito" e a concepção de um "eu" entendido como "causa de todo fazer, como agente", e apresenta a tese segundo a qual os postulados lógico-metafísicos da tradição filosófica, como o de substância, por exemplo, foram construídos a partir da ideia de sujeito e do hábito arraigado em nossa cultura "de considerar todo o nosso fazer como consequência de nossa vontade". Conferindo, portanto, uma centralidade ao tema do sujeito em relação à metafísica, Nietzsche abre uma polêmica contra o pressuposto daqueles postulados afirmando que "não existe [...] nenhuma vontade", do mesmo modo como não existe um "sujeito - "átomo", que se manteria para além das circunstâncias nas quais aparece e se modifica, ${ }^{25}$ pois a própria ideia de sujeito, ou de eu, seria um produto histórico, cujas raízes descem até "a mais antiga cisão ('respirar', 'viver') - " (Nachlass/FP, 1887, 9 [98], KSA 12.391).

A importância desse fragmento, contudo, não reside apenas na retomada da crítica do filósofo ao sujeito entendido como unidade da vontade e no fato de conferir uma primazia do conceito de sujeito sobre os postulados da metafísica, mas no quanto ele permite ampliar as possibilidades de se pensar o tema. $\mathrm{O}$ que se verifica em especial

24 Na seção "Os desprezadores do corpo" de Assim falou Zaratustra, o termo "eu" aparece não com algo que é "dito", mas "feito". O "eu" é feito justamente a partir da grande razão que é o corpo. O corpo confere o sentido ao que é conhecido, sentido e, no geral, atribuído ao "eu". (Za/ZA Os desprezados c corpo, KSA 4.39).

25 Radicalizando a proposição de Kant, contrária à possibilidade de se conhecer a "coisa em si" (Kant, 1995, p. 27), Nietzsche afirma que não possuímos qualquer "órgão de conhecimento" que nos permitiria fazer uma divisão entre uma "coisa em si" e um mundo entendido como aparência (FW/GC 354, KSA 3.593) 
Paschoal, A. E.

na menção feita nele à "esfera de um sujeito constantemente se ampliando ou se diminuindo - o ponto médio do sistema se deslocando constantemente -; [um sujeito que] no caso de não conseguir organizar a massa adquirida, divide-se em dois". Uma esfera, portanto, que comporta uma pluralidade multifacetada, no interior da qual é possível apontar tanto um "sujeito mais fraco", que pode ser convertido em um "funcionário", quanto seu oposto, que comanda. No interior da qual também é possível identificar configurações momentâneas ou unidades provisórias que no seu extremo remetem a estabilidades relativas, mas, em caso algum, à ideia de "substância". (Nachlass/ FP, 1887, 9 [98], KSA 12.391-392)

Portanto, se "não existe" aquela substância e nem aquele "sujeito-átomo", nem por isso o termo "sujeito" é descartado pelo filósofo, que associa ao conceito um universo plural e instável. Uma ideia traduzida por João Constâncio como "uma multiplicidade de processos inconscientes de sentimentos, vontades e pensamentos que não são causados nem controlados por um 'eu"' 26 . Algo que na obra publicada de Nietzsche aparece como um "sujeito múltiplo" em contraposição àquele "atomismo da alma" (JGB/BM 12, KSA 5.27), remetendo a uma pluralidade de seres que lutam entre si, com alternâncias de domínio e que "em parte permanecem inconscientes para nós e <em parte> se acham conscientes sob a forma de impulsos" (Nachlass/FP, 1884, 27 [27], KSA 11.282).

No âmbito de tal concepção, o propósito de compreender uma ação deveria considerar esse complexo campo de pontuações de poder, ora se agrupando e formando partidos, ora entrando em conflito e opondo-se umas às outras, de forma aberta ou velada, cada uma delas buscando não apenas a conservação, mas o "fortalecimento" (FP do outono de 1887, 9 [98], KSA 12.392) Contudo, tal concepção ainda não encerra o complexo horizonte dos modos como a filosofia de Nietzsche permite retomar o tema do sujeito. Mesmo porque, no seu

26 Constâncio, 2015, p. 286.

108 | Cad. Nietzsche, Guarulhos/Porto Seguro, v.39, n.1, p. 93-119, janeiro/abril, 2018. 
âmbito, ainda permanece o risco de se retomar, no essencial, aquilo que o filósofo quis eliminar, já que a consideração da pluralidade do sujeito, mesmo conferindo uma visão mais abrangente e detalhista do processo no qual se tem a ação, poderia manter ainda a ideia de um agente por trás da ação. Nietzsche não teria, assim, se livrado dos postulados que critica. Em especial não teria se livrado do princípio de causalidade, pois manteria ainda a ideia de um sujeito atuante, com a diferença que esse agente seria plural e nem sempre compreendido em toda a sua complexidade. Por esse motivo, à possibilidade de se pensar o sujeito como expressão de uma realidade plural, instável e provisória, é preciso acrescentar ainda uma ideia de sujeito que se traduz retomando a ideia de ficção.

\section{Da crítica do sujeito como ficção ao sujeito possível... como ficção}

A retomada do tema do sujeito a partir da ideia de ficção recoloca necessariamente o problema da consciência de si em Nietzsche. O primeiro ponto a ser considerado, nesse sentido, é que os elementos múltiplos que constituem o sujeito "em parte permanecem inconscientes para nós e [no máximo] se acham conscientes sob a forma de impulsos", ou seja, eles não são alcançados pela consciência. $\mathrm{O}$ segundo ponto é que em grande parte esse sujeito é condicionado por fatores advindos de um passado que "nos alcança e reverbera em nós" (GM/GM, II 3, KSA 5.295). O fato, porém, é que muitos daqueles fatores não deixam de ser, também eles, inventados por nós, "fingidos" e que, "apenas como um vapor tem efeito sobre nós" (M/A 307, KSA 3.225). ${ }^{27}$ Assim, a transposição de uma concepção possível

27 Nas palavras de Martin Saar, sujeito, espírito e consciência seriam, para Nietzsche, "menos pontos fixos fundamentados do que pontos de constructos interpretativos por processos dinâmicos" (Saar, 2007, p. 102). Assim, o mesmo termo [sujeito] utilizado para designar um universo complexo, designa também o resultado de um intrincado conflito entre vontades de poder que se manifesta na forma de uma moral e de uma cultura, que são produtoras de subjetividades. 
de sujeito em Nietzsche para o problema de sua exposição requer algumas ponderações prévias sobre a questão da consciência e da linguagem em Nietzsche, além da observação de certas peculiaridades do modo como ele usa a linguagem.

Em linhas gerais, a linguagem é entendida por Nietzsche como produtora de sinais, uma semiótica que, para efeitos de comunicação, simplifica a pluralidade de afetos que é o homem e a reduz a um conjunto de signos. Num universo, portanto, em que "a maioria das atividades mais importantes é inconsciente", o "eu-consciente" teria um papel tão importante quanto limitado na designação do que é assimilado pelo corpo e o constitui (Nachlass/FP, 1881, 11 [316], KSA 9.564).

Mais, porém, do que um espelho opaco face ao que se passa no corpo, a ser avaliado por sua incapacidade de expressar em toda a sua complexidade os processos de assimilação de vivências que se passam no corpo, esse "eu-consciente" precisa ser visto como o resultado de vivências passadas que foram assimiladas pelo corpo em processos de subjetivação ${ }^{28}$. Vivências e modos de assimilação que se inter-relacionam delineando não um sujeito possuidor de um livre arbítrio, mas um sujeito que não pode ser separado de seu agir, mas que é identificado pelo seu modo de agir. Ele é o seu agir, é reconhecido por ele e não pode ser separado dele. Desse modo, a exposição de si pela consciência, conquanto se manifeste como se tivesse um caráter voluntário, não deixa de ser uma expressão do que se é. Assim, não apenas não podemos nos tornar o que não somos, como também não podemos nos expressar em desacordo com o que somos.

28 Essa tese não é nova. Para João Constâncio (2015, p. 315), por exemplo, a introdução do conceito de subjetividade constitui o ponto de virada de Nietzsche em relação ao tema do sujeito que se tem na modernidade. Martin Saar (2007), por sua vez, destaca o papel Genealogia da moral em mostrar modos como se constituem subjetividades no Ocidente, em especial a partir da moral. François Kammerer (2008), ao seu modo, introduz a noção de subjetividade em seu estudo de Ecce homo, que interpreta como uma forma peculiar de autobiografia, de narrativa de si pelo filósofo.

110 | Cad. Nietzsche, Guarulhos/Porto Seguro, v.39, n.1, p. 93-119, janeiro/abril, 2018. 
O reconhecimento de si do sujeito, dos seus traços característicos e do seu modo próprio de agir, se dá pelo olhar para as suas ações anteriores e também para as condições de sua emergência e transformação e pelo modo como o seu corpo assimila essas condições. Tal reconhecimento se faz por meio de um levantamento genealógico desse sujeito, numa genealogia de si ou autogenealógia, ${ }^{29}$ que permite a ele apresentar seus traços próprios, isto é, seu modo de agir. Precisamente o que se tem, por exemplo, no prólogo da Genealogia da moral. Um texto deliberadamente formulado em primeira pessoa para caracterizar não um sujeito livre por trás do texto, mas um modo de agir, uma configuração possível e um modo de fazer polêmica que se torna possível precisamente no ambiente criticado por ele.

Tal genealogia de si seria, assim, uma genealogia de certos pensamentos, escrúpulos e hipóteses, com a descrição do quando e como eles surgiram (GM/GM, Prólogo 2 e 4, KSA 5.248-251), por que surgiram (5 e 6, KSA 5.251-253) se modificaram (3 e 7, KSA 5.249250 e KSA 5.254-255) e como se apresentam (8, KSA 5.255-256). Nesse texto, um modo de agir e de se posicionar diante da moral se coloca para o leitor na figura do autor, o qual como um sujeito pode apresentar aquilo que $o$ incomoda, por exemplo, a possibilidade de um budismo europeu; as exigências que se colocam a ele, por exemplo, de uma crítica do valor dos valores, de se confrontar com seu grande mestre, Schopenhauer (5, KSA 5.251-252); bem como a aversão produzida nele pelo livro do Dr. Paul Rée (4, KSA 5.250-251), seu amigo em outros tempos; e até mesmo suas incursões infantis sobre a origem do mal e o que significou para ele o conhecimento histórico e de filologia (3, KSA 5.249-250).

29 Desenvolvemos uma interpretação do conceito de autogenealogia em associação à tese que conduz este estudo, de que a exposição de si constitui uma estratégia filosófica na obra de Nietzsche, num estudo intitulado "Autogenealogia: acerca do tornar-se o que se é" (Paschoal, 2015, pp. 27-44). 
Paschoal, A. E.

Com essa descrição, parece colocar-se diante do leitor um homem que reconhece e demarca a sua posição no jogo em que está inserido, com aquela honestidade intelectual que não esconde a posição interpretativa assumida nem reivindica uma posição neutra que se encontraria, talvez, acima do jogo no qual se insere e busca produzir efeitos de poder. Neste ponto, porém, em que Nietzsche faz seu leitor experimentar o efeito sedutor de sua linguagem, especialmente por meio da descrição detalhada de si, não se pode esquecer que tal narrativa é precedida de uma dura advertência, de que "nós homens do conhecimento, não nos conhecemos, de nós mesmos somos desconhecidos" (GM/GM, Prefácio 1, KSA 5.247-248).

Tendo em vista essa advertência, a apresentação de si de Nietzsche não poderia corresponder a uma descrição objetiva de si. Antes, precisaria ser concebida, também ela, como parte do trabalho ficcional que se desdobra na obra. Assim, do mesmo modo como se tem como no caso do "raio e do clarão", em que o segundo não é a ação, um efeito "de um sujeito de nome raio", também nesse caso, não se poderia separar autor e obra, como se a segunda fosse efeito do primeiro. Nesses termos, é possível aventar a hipótese de que a biografia, ao ultrapassar a tênue linha que divide a vida e a obra, ao entrar na obra, deixa de ser biografia e se torna argumento, personagem, parte da ficção.

Como vimos anteriormente, o termo ficção é utilizado por Nietzsche no sentido de uma crença que "introduz uma falsa realidade" (Nachlass/FP, 18879 [144], KSA 12.417), como um equívoco da razão. Existem, contudo, dois modos diferentes como o termo ficção é encontrado na filosofia de Nietzsche. O primeiro, criticado por ele, tem o sentido de uma falsificação que se torna objeto de crença. Tratase, por exemplo, do mundo ficcional apontado por conceitos como "Deus", "vida eterna" etc. em O Anticristo (AC/AC 15, KSA 6.181) ou ainda de uma "ficção lógica", que em Além do bem e do mal indica um equívoco da razão, por exemplo, quando os juízos remetem a algo 
"puramente inventado" (JGB/BM 4, KSA 5.18). O segundo, enaltecido por ele, tem um sentido de obra de arte, poético, de dissimulação, fantasia e criação. Trata-se da "linguagem dos pintores", que não remete a "verdadeiro e falso", mas a "graus de aparência" (JGB/ BM 34, KSA 5.53). Em termos pontuais, essa linguagem se torna útil, por exemplo, numa contraposição às convicções metafísicas, que só teriam direito à cidadania no reino do conhecimento caso não se apresentassem como convicções, mas com a "modéstia de uma hipótese" ou, mais especificamente, como uma "ficção reguladora", ou seja, assumindo um "ponto de vista experimental e provisório" (FW/GC 344, KSA 3.574). Em termos mais amplos, ela corrobora a tese de que "o mundo para Nietzsche é um produto da interpretação e da projeção do homem" ${ }^{30}$ e também que todo homem, de algum modo, é um "artista" (FW/GC, 356, KSA 3.595) e que a vida do homem ao certo não poderia ser pensada sem a ficção.

Tendo em vista esse segundo modo como o termo ficção aparece nos escritos de Nietzsche, é possível afirmar que o problema não se encontraria no fato de o homem inventar ficções, visto que tudo "o que pode ser pensado, é seguramente uma ficção" (Nachlass/FP, 1888 14[148], KSA 13.332) e também que as ficções fazem parte da vida, que o caráter ficcional "é condição da vida" (JGB/BM 4, KSA 5.18). Desse modo, desvinculada de uma profissão de fé e reconhecida como uma ilusão, a ficção não poderia ser dispensada pelo homem, sendo útil, por exemplo, na escrita do filósofo e na compreensão do modo como ele utiliza a linguagem.

Considerando o caráter ficcional do mundo, Nietzsche propõe, pela boca de um suposto interlocutor, uma questão essencial: "mas a ficção não requer um autor [Urbeber]?". A essa pergunta, não apresenta uma resposta, mas outra pergunta, no caso, formulada por ele mesmo: "Esse 'requer' não pertenceria também à ficção?" (JGB/ BM 34, KSA 5.54). Em outros termos, inversamente à questão inicial,

30 Martínez, 2013, p. 149. 
Paschoal, A. E.

teríamos: a exigência do autor não seria uma exigência da própria ficção? Em resumo, num texto em que trata justamente do sujeito e da necessidade de o filósofo "se colocar acima da gramática" e da "fé na gramática" (JGB/BM 34, KSA 5.54), Nietzsche permite associar o autor à ficção, como parte da ficção. De tal modo que, se tomamos a sua proposição: "uma coisa sou eu, outra são meus escritos" (EH/EH, Por que escrevo livros tão bons, 1, KSA 6.298), torna-se necessário atentar para o fato de que a figura Nietzsche, incluindo as vezes em que aparece na forma do pronome pessoal "eu", faz parte da obra, dos escritos, e não poderia ser tomado simplesmente como uma descrição biográfica do homem franzino, doente e atribulado, o filho da Dona Franziska e Karl Ludwig, que estaria sentado atrás da escrivaninha redigindo aquela passagem. A hipótese, portanto, de que a biografia, ao entrar na obra deixa de ser biografia, se torna argumento, deve ser considerada, no mínimo, como uma hipótese reguladora, ao menos como parte de uma interpretação justificada da filosofia de Nietzsche.

Tendo em vista essa hipótese e lembrando que não é apenas o caráter denotativo e descritivo o que permite a Nietzsche configurar personagens, mas em especial o caráter ficcional da linguagem, é possível mesmo avançar para a conjetura de que o sujeito que aparece nos seus textos, assim como o uso do pronome pessoal "eu" e, em última instância, da figura denominada como o "Senhor Nietzsche" (FW/GC, Prefácio 2, KSA 3.347) é parte da cena que se tem no texto. Uma parte na qual se concentram os traços, a "morfologia" (JGB/BM 23, KSA 5.38) de um modo de agir, de um sujeito capaz de superar o seu tempo.

Dessa forma e reiterando que a linguagem não tem como finalidade expressar o mundo ou "a verdade" (FW/GC 354, KSA 3.593) de algo e também que seria uma empreitada fadada ao fracasso uma exposição de si que não considerasse o caráter ficcional dessa exposição, mesmo uma autogenealogia não poderia ser dissociada

114 | Cad. Nietzsche, Guarulhos/Porto Seguro, v.39, n.1, p. 93-119, janeiro/abril, 2018. 
da ideia de um trabalho de artista que, em certa medida, inventa, representa e interpreta a si mesmo como um sujeito possível, ${ }^{31}$ ao lado do qual outros serão necessários, como é o caso de Zaratustra, Dionísio, Espírito Livre etc. Cada um funcionando, a cada momento, como uma máscara, atrás da qual não existe um substrato, mas outra máscara.

\section{Mais uma máscara... e muitas máscaras}

A ideia de uma ficção que permite ultrapassar o caráter denotativo da linguagem e a articulação da fala para além do campo denotativo, nos conduz a uma possibilidade extremamente produtiva de pensar o sujeito a partir da crítica de Nietzsche ao sujeito. Uma possibilidade no interior da qual o sujeito que fala não é uma substância, mas uma máscara, um personagem ou uma "figura de pensamento", nas palavras de Christian Hick, ${ }^{32}$ que divide a cena do texto não apenas com outros personagens, mas com outros sujeitos.

Vários exemplos de personagens, no sentido aqui indicado, são encontrados, por exemplo, na Genealogia da moral, expressando diferentes modos de agir e cumprindo diferentes papéis na obra. Além de figuras clássicas como a dos psicólogos ingleses, antigas aristocracias, sacerdotes, judeus etc., ganha destaque no texto algumas situações em que o papel a ser desempenhado não caberia ao "senhor Nietzsche" que, por exemplo, na seção 14 da primeira dissertação,

31 Michel Foucault, em seu clássico texto intitulado "O que é um autor", refere-se à função autor. No âmbito de tal concepção, o sujeito que fala não seria o "sujeito em uma linguagem" (Foucault, p. 268), com um nome próprio, ou um princípio de unidade na escrita, mas um nome que "funciona para caracterizar um certo modo de ser do discurso" (Foucault, p. 273). Um modo de exposição que corresponderia, ainda ao que Foucault chama de "função autor" (Foucault, p. 274), permitindo caracterizar o falante, um suposto "eu" que fala, sem descartar a pluralidade de figura que podem ocupar esse lugar. No caso, o sujeito em questão não é a figura sentada na mesa de trabalho, conferindo autoridade ao texto e respondendo por ele, mas o autor como parte do texto, o que seria, para Foucault, "uma das especificações possíveis da função sujeito" (p. 287).

32 Hick, 2000, p. 87.

Cad. Nietzsche, Guarulhos/Porto Seguro, v.39, n.1, p. 93-119, janeiro/abril, 2018. 
cede o lugar no texto ao "senhor Curioso e Temerário" (GM/GM, I 14, KSA 5.281), passando ele, o "senhor Nietzsche", à condição de quem escuta apenas. De fato, nesse caso, as afirmações absurdas que aparecem no texto não poderiam ser fruto daqueles pensamentos expostos em primeira pessoa no Prólogo. Do mesmo modo, outra máscara é exigida quando o discurso ganha um tom demasiado profético e o autor se flagra anunciando: "esse homem do futuro (...) esse vencedor de Deus e do nada - ele tem que vir um dia..." (GM/ GM, II 24, KSA 5.336) e imediatamente se cala, pois tal pretensão só seria permitida "a um mais jovem, a um 'mais futuro', a um mais forte do que eu - o que tão só a Zaratustra se consente, a Zaratustra, o ateu..." (GM/GM, II 25, KSA 5.337). Zaratustra, a máscara que possibilita certas inflexões que ao "senhor Nietzsche" não seriam permitidas sob a pena de se perder a coerência para com a própria máscara do genealogista.

Roberto S. Martínez apresenta uma tese plausível para explicar esse aparecimento de vários sujeitos no texto de Nietzsche. Segundo ele, a obra de Nietzsche reúne, por um lado, essa multiplicidade de formas e rostos e, por outro, "uma visão de mundo egocêntrica" 33 , que se apresenta em primeira pessoa, numa linguagem autorreferencial. A relação entre esses dois aspectos se faria por meio de uma "poetologia do si mesmo" [Poetologie des Selbst], compreendida como um processo não tanto de autoconhecimento, mas de automodelação ou autoencenação, que passaria por ou ganharia diferentes formas. Embora seja uma tese interessante, o fato é que essa interpretação ainda mantém a primazia do próprio Nietzsche como um sujeito abrangente que, de certo modo, representa outros personagens e, de certa maneira, se coloca acima da cena, controlando-a. Ao passo que aqui interessa distinguir o senhor Nietzsche em seus limites e possibilidades, ao lado de outras figuras necessárias, no interior da obra.

33 Martínez, 2013, p. 153.

116 | Cad. Nietzsche, Guarulhos/Porto Seguro, v.39, n.1, p. 93-119, janeiro/abril, 2018. 
Porquanto, arriscando ultrapassar a tênue linha que separa o encontrar [finden] do inventar [erfinden], que aparta o que poderíamos chamar de Nietzsche histórico do personagem Nietzsche, aventamos a hipótese de que uma das possibilidades mais interessantes para pensar e utilizar a ideia de sujeito nos escritos é a que aproxima o "senhor Nietzsche" de um personagem. Uma possibilidade no interior da qual o "senhor Nietzsche" se torna extremamente atraente (FW/GC, Prefácio 2, KSA 3.347) e deve ser levado a sério como o sujeito da crítica de Nietzsche ao sujeito, especialmente porque esse sujeito não é um agente livre, mas um modo de agir que permite, por exemplo, "superar em si o seu tempo, tornar-se atemporal" (WA/ CW, Prólogo, KSA 6.11).

\begin{abstract}
The ambiguity of the title of this article reflects the multifaceted character of a problem that has in its horizon, on the one hand, Nietzsche's harsh critic of the subject and, on the other hand, the possibilities opened by this critic, either in the direction of a plural subject, a thesis clearly delineated in Nietzsche's writings, or in the sense of a fictional subject, that apears in the text of the philosopher, clearly contradicting the idea of subject criticized by him. Considering, therefore, the controversial character of the question, the purpose of this study is to point out some central features of Nietzsche's critique of the subject in order to show that it is precisely from this critique that is precisely from this critique that new possibilities are outlined to think and use the idea of subject in his writings.
\end{abstract}

Keywords: Nietzsche, subject, subjectivity, critique, self genealogy. 
Paschoal, A. E.

\section{Referências bibliográficas}

AgOSTINHO. Confissões. Trad. Angelo Ricci. São Paulo: Abril Cultural, 1973.

AQUINO, Tomás de. O livre arbitrio. Quaestiones disputatae. De Veritate: Questão 24. Trad. Paulo Faitanin e Bernardo Veiga. São Paulo: EDIPRO, 2015.

CONSTÂNCIO, João. Nietzsche on Decentered Subjectivity or, the Existential Crisis of the Modern Subject. In: CONSTÂNCIO, João; MAYER BRANCO, Maria João; RYAN, Bartholomew (orgs.). Nietzsche and the Problem of Subjectivity. Berlin/Boston: De Gruyter, 2015, p. 279-316.

DESCARTES, René. Discurso do Método. As paixões da alma. Meditações. Objeções e respostas. Trad. de J. Guinsburg e Bento Prado Junior. $5^{\text {a }}$ ed. São Paulo: Nova cultural, 1991. (Os Pensadores)

FOUCAULT, M. O que é um autor? In: Ditos e escritos III. Org. Manoel Barros da Motta. Trad. Inês Autran Dourado Barbosa. Rio de Janeiro: Forense Universitária, 2001.

FOUCAULT. M. A verdade e as formas jurídicas. Trad. De Roberto Cabral de Melo Machado e Eduardo Jardim Morais. Rio de Janeiro: NAU Editora, 2002.

HEIDEGGER, M. Nietzsche II. Trad. Marco Antonio Casanova. Rio de Janeiro: Forense Universitária, 2007.

HICK, Christian. Denken als Symptom - Symptome als Gedanken. Zur Kreisgestalt von Nietzsches "grosser Gesundheit". In: Nietzscheforschung, Jahrbuch der Nietzsche-Gesellschaft, 5/6, Akademie Verlag GmbH, Berlin, 2000.

ITAPARICA, A. L. M. Crítica à modernidade e o conceito de subjetividade em Nietzsche. In: Estudos Nietzsche, Curitiba, v. 2, n. 1, p. 59-78, jan./jun. 2011.

KANT, I. Kritik der reinen Vernunft 1. Werkausgabe Band III, Herausgegeben von Wilhelm Weischedel. Frankfurt am Main: Suhrkamp, 1995.

KANT, Immanuel. Kritik der praktischen Vernunft. Grundlegung zur Metaphysik der Sitten. Frankfurt am Main: Suhrkamp, 1996.

KAMMERER, François. Nietzsche, le sujet, la subjectivation. Une lecture d'Ecce homo. Paris: L'Harmattan, 2008.

118 | Cad. Nietzsche, Guarulhos/Porto Seguro, v.39, n.1, p. 93-119, janeiro/abril, 2018. 
MARTÍNEZ, Roberto Sanchiño. “Aufzeichnungen eines Vielfachen”. Zu Friedrich Nietzsches Poetologie des Selbst. Bielefeld: Transcript Verlag, 2013.

MARTON, Scarlett. Nietzsche e Descartes: Filosofias de Epitáfio. In: Extravagâncias. Ensaios sobre a filosofia de Nietzsche. 3. ed. São Paulo: Discurso Editorial; Editora Barcarolla, 2009, p. 143-166.

NIETZSCHE, Fr. Kritische Studienausgabe. 15 Bände. Herausgegeben von Giorgio Colli und Mazzino Montinari. Berlin/New York: de Gruyter, 1988.

ONATE, A. M. O crepúsculo do sujeito em Nietzsche ou como abrir-se ao filosofar sem metafísica. São Paulo: Discurso Editorial, 2000.

PASCHOAL, A. E. Autogenealogia: acerca do tornar-se o que se é. In: Revista Dissertatio, 42, 27-44, verão de 2015.

SAAR, M. Genealogie als Kritik. Geschichte und Theorie des Subjekts nach Nietzsche und Foucault. Frankfurt/New York: Campus Verlag, 2007.

WIENAND, Isabelle. Writing from a First-Person Perspective: Nietzsche's Use of the Cartesian Model. In: CONSTÂNCIO, João; MAYER BRANCO, Maria João; RYAN, Bartholomew (orgs.). Nietzsche and the Problem of Subjectivity. Berlin/Boston: De Gruyter, 2015, p. 49-64.

Artigo recebido para publicação em 26/05/2017 Artigo aceito para publicação em 11/08/2017 